\title{
Research Article \\ Fractional Order Nonlinear Feedback Controller Design for PMSM Drives
}

\author{
Jian-Ping Wen \\ School of Mechanical Engineering, Xian University of Science and Technology, Xian, \\ Shaanxi 710054, China \\ Correspondence should be addressed to Jian-Ping Wen; wenegle@gmail.com
}

Received 4 November 2012; Revised 10 March 2013; Accepted 11 March 2013

Academic Editor: M. Onder Efe

Copyright @ 2013 Jian-Ping Wen. This is an open access article distributed under the Creative Commons Attribution License, which permits unrestricted use, distribution, and reproduction in any medium, provided the original work is properly cited.

\begin{abstract}
Fractional order integral is introduced into active disturbance rejection controller (ADRC) to establish the structure of fractional order proportional integral controller (FPI). Fractional order ADRC (FADRC) is designed by replacing the nonlinear state error feedback control law using nonlinear function combination in ADRC with FPI, which can combine the high performance of ADRC estimating disturbances with the characteristics of fractional order calculus more really describing the physical object and spreading the stable region of the system parameters. The proposed FADRC is applied to permanent magnet synchronous motor (PMSM) speed servo system in order to improve robustness of system against the disturbances. Compared with ADRC, simulation results verify that the proposed control method has given very good robust results and fast speed tracking performance.
\end{abstract}

\section{Introduction}

Permanent magnet synchronous motor (PMSM) is increasingly used in high precise AC servo driving control system due to its simple structures, high efficiency, low inertia, high power density and high torque-current ratio. PMSM is a nonlinear, strong coupling, and multivariable controlled object, which makes the system become nonlinear system with strong coupling [1-3]. To cope with parameter uncertainty, load disturbance, strong coupling, and measurement noise, and so forth, many control strategies, such as PI control $[4,5]$, adaptive control $[6,7]$, sliding mode control $[8,9]$, $H_{\infty}$ control $[10,11]$, and intelligent control [12-15], have been developed and applied to the speed control of speed servo drives to obtain high driving performance and exploit advantage of PMSM. PI control can hardly meet the requirement of high performances although it was widely used. There exists complex adaptive control law in adaptive control. Chattering phenomenon can be caused in a conventional sliding mode control system. Due to these questions, the fields of use with those control techniques were restrained. Besides in recent years, active disturbance rejection control technique is applied in PMSM speed servo system [16-18], which can design the controller of controlled object by using order of model, but not becoming dependent. It improves the response of system by using extended state observer to estimate and compensate disturbances. Reference [19] proposed fractional order proportional integral differential controller by using tracking differentiator to obtain tracking signal of output and its differential signal.

Fractional order calculus extends integer order ones to nonintegral order, which can model various real materials more adequately than integer order ones. This study introduces fractional order calculus into ADRC and establishes the structure of fractional order proportional integral controller. Fractional order ADRC is designed by replacing the nonlinear state error feedback control law using nonlinear function combination in ADRC with FPI, which can combine the high performance of ADRC estimating disturbances with the characteristics of fractional order calculus more really describing the physical object and spreading the stable region of the system parameters. The proposed FADRC is applied to permanent magnet synchronous motor speed servo system in order to improve robustness of system against the disturbances. Compared with ADRC, simulation results verify that the proposed control method has given very good robust results and fast speed tracking performance. 


\section{ADRC of PMSM Speed Servo System}

On the basis of assumptions that the stator windings generate sinusoidal magnetic field, air gap is uniform and saturation is negligible. With reference to synchronous rotating reference frame, the dynamical rotate speed equation of PMSM may be expressed as follows:

$$
\frac{d \omega}{d t}=-\frac{B}{J} \omega-\frac{T_{L}}{J}+p_{n} \frac{\psi_{f}}{J} i_{q},
$$

where $i_{q}$ is stator $q$-axis currents; $\psi_{f}$ is amplitude of the flux induced by the permanent magnets of the rotor in the stator phases; $\omega$ is angular speed of the motor; $p_{n}$ is number of pole pairs; $J$ is inertia of moment; $T_{L}$ is the load torque; $B$ is viscous friction coefficient.

To facilitate the design of ADRC, the rotate speed equation can be expressed as

$$
\frac{d \omega}{d t}=f_{0}+g_{\omega}+b_{0} \cdot i_{q}
$$

where $f_{0}=-(B / J) \omega$ is known information of model, function of which is to minish total observed disturbances and exploit known information of model to improve velocity of convergence and accuracy of observation in observation of ESO; $g_{\omega}=-T_{L} / J$ is disturbance term of model; $b_{0}=$ $\left(\left(3 p_{n} \psi_{f}\right) / 2 J\right)$.

For the second-order system, type structure of ADRC includes tracking differentiator (TD), extended state observer (ESO), nonlinear state error feedback control law (NLSEF), and compensated control reference [20]. PMSM speed servo system using vector control is first-order model. In which the tracking differentiator plays a filter action role and can be omitted. So, ADRC of system is expressed as

ESO

$$
\begin{gathered}
e=\widehat{\omega}-\omega, \\
\dot{\omega}=g_{\omega}+z_{0}-\beta_{01} \cdot \operatorname{fal}\left(e, \frac{1}{2}, \delta\right)+b_{0} \cdot i_{q}, \\
\dot{z}_{0}=\beta_{02} \cdot \operatorname{fal}\left(e, \frac{1}{4}, \delta\right),
\end{gathered}
$$

where $\widehat{\omega}$ is observing signal of rotate speed; $\omega$ is rotate speed of motor; $z_{0}$ is disturbance estimation; $\beta_{01}$ and $\beta_{02}$ are gain factor, respectively.

NLSEF

$$
\begin{gathered}
e_{0}=\int e_{1} d t, \\
e_{1}=\omega^{*}-\widehat{\omega}, \\
u_{0}=\beta_{1} \mathrm{fal}\left(e_{0}, \frac{1}{2}, \delta\right)+\beta_{2} \mathrm{fal}\left(e_{1}, \frac{1}{4}, \delta\right),
\end{gathered}
$$

where $\omega^{*}$ is input reference; $e_{0}$ is error integral; $e_{1}$ is error; $\beta_{1}$ and $\beta_{2}$ are gain factor, respectively. fal $(\cdot)$ is nonlinear function.

Disturbance compensation

$$
i_{q}^{*}=u_{0}-\frac{\left(f_{0}+z_{0}\right)}{b_{0}}
$$

$i_{q}^{*}$ is input reference with disturbance compensation.

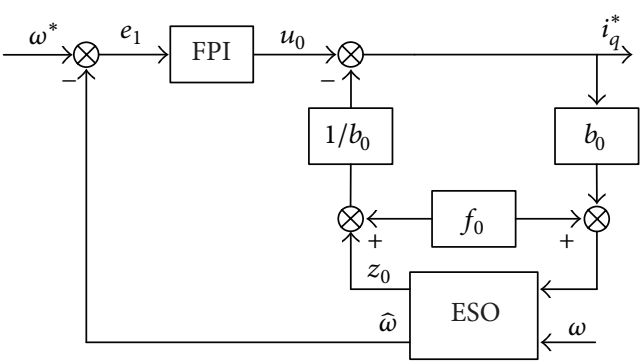

FIgURE 1: The block diagram of fractional order ADRC.

\section{Design of FADRC}

Fractional order calculus is a basic subject with mathematics to study differential coefficient and integral of random order, which can be expressed in calculus operator of fractional order and integral order [21]

$$
D_{t}^{\lambda}= \begin{cases}\frac{d^{\lambda}}{d t^{\lambda}}, & R(\lambda)>0 \\ 1, & R(\lambda)=0 \\ \int_{a}^{t}(d \tau)^{-\lambda}, & R(\lambda)<0,\end{cases}
$$

where $a$ is lower bound of calculus operator; $t$ is upper bound of calculus operator; $\lambda$ is order number of calculus operator; order number of calculus equals integral order when $\lambda$ is integer; $R(\lambda)$ represents real number; $D_{t}^{\lambda}$ indicates fractional differentiation when $R(\lambda)$ is greater than zero; $D_{t}^{\lambda}$ indicates fractional differentiation when $R(\lambda)$ is less than zero.

Fractional order calculus extends the order number of calculus to fraction. Nonsmooth feedback of NLSEF in ADRC is replaced with the nonlinear fractional order PI controller, which combines the high performance of ADRC estimating disturbances with the characteristics of fractional order calculus more really describing the physical object and spreading the stable region of the system parameters. The structure of fractional order PI controller can be established by putting the $\lambda<0$ into (4). So, the nonlinear error feedback in FADRC can be expressed as

$$
\begin{gathered}
e_{1}=\omega^{*}-\widehat{\omega}, \\
u_{0}=k_{1} e_{1}+k_{2} D_{t}^{-\lambda} e_{1},
\end{gathered}
$$

where $k_{1}$ is proportion coefficient; $k_{2}$ is integral coefficient; $\lambda$ is order of integral; the block diagram of FADRC is shown in Figure 1.

By using Laplace transform, transfer function for $u_{0}$ and error is inferred as follows:

$$
G(s)=\frac{U_{0}(s)}{E(s)}=k_{1}+k_{2} s^{-\lambda}
$$

In order to obtain discrete mathematical model of numerical control to be used, it is required that fractional order integral operator is approximately discretized. Using Euler 


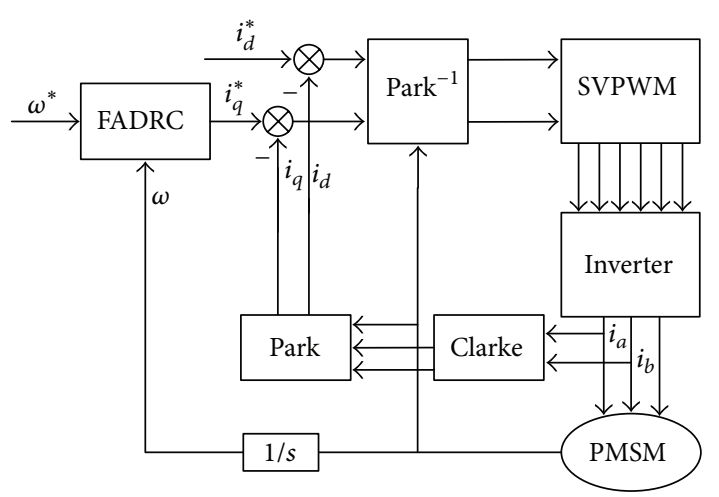

FIgURE 2: The block diagram of PMSM speed servo system.

rule transform method, the fractional order system can be discretized into irrational equation of $z$, which is then transformed in the power series expansion (PSE) way to obtain discrete model of $s^{-\lambda}$, as follows:

$$
Z\left(s^{-\lambda}\right) \approx\left(\frac{1}{T}\right)^{-\lambda} \operatorname{PSE}\left[1+\lambda z^{-1}+\frac{\lambda(1+\lambda)}{2 !} z^{-2} \ldots\right],
$$

where $T$ is sampling period; when $\lambda$ equals $0.3, T$ is $0.001 \mathrm{sec}$., and the degree of polynomial is 10 , the approximate discretized model of fractional order integral is obtained as follows:

$$
Z\left(s^{-0.3}\right) \approx \frac{1}{D}
$$

where $D$ is expressed as follows:

$$
\begin{aligned}
D= & 7.9428-2.3828 z^{-1}-0.834 z^{-2}-0.4726 z^{-3} \\
& -0.319 z^{-4}-0.2361 z^{-5}-0.1849 z^{-6} \\
& -0.1506 z^{-7}-0.1261 z^{-8}-0.1079 z^{-9} .
\end{aligned}
$$

The block diagram of PMSM speed servo system is shown in Figure 2.

\section{Simulation Results and Analysis}

The proposed method is investigated by means of simulations. The Matlab/Simulink environment is used for the simulations. The data of the PMSM are as follows: the nominal power is $1.8 \mathrm{~kW}$; the nominal dc-link voltage is $72 \mathrm{~V}$; the nominal torque is $5 \mathrm{~N} \cdot \mathrm{m}$; the number of poles is 4 ; the moment of inertia is $0.012 \mathrm{~kg} \cdot \mathrm{m}^{2}$; the stator resistance is $0.09 \Omega$; the direct-axis inductance and quadrature-axis inductance are $0.4 \mathrm{mH}$ and $0.5 \mathrm{mH}$, respectively; sampling period of current loop is set to $2 \mu \mathrm{s}$, in which the vector control of $i_{d}=0$, two proportional-integral (PI) discretetime current controllers for $i_{d}$ and $i_{q}$, are used; speed loop is regulated by FADRC, $\delta=0.01 ; \beta_{01}=10000$ and $\beta_{02}=$ 500000; fraction value of fractional order integral is selected by means of trial and error; the discrete mathematical model is given by (10).

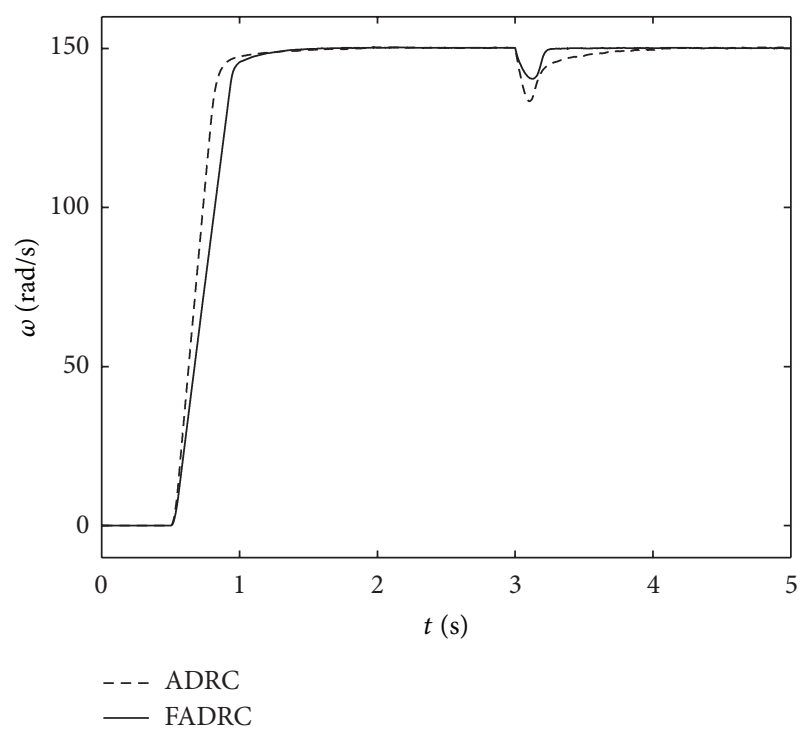

FIGURE 3: Speed response to impulse load disturbance.

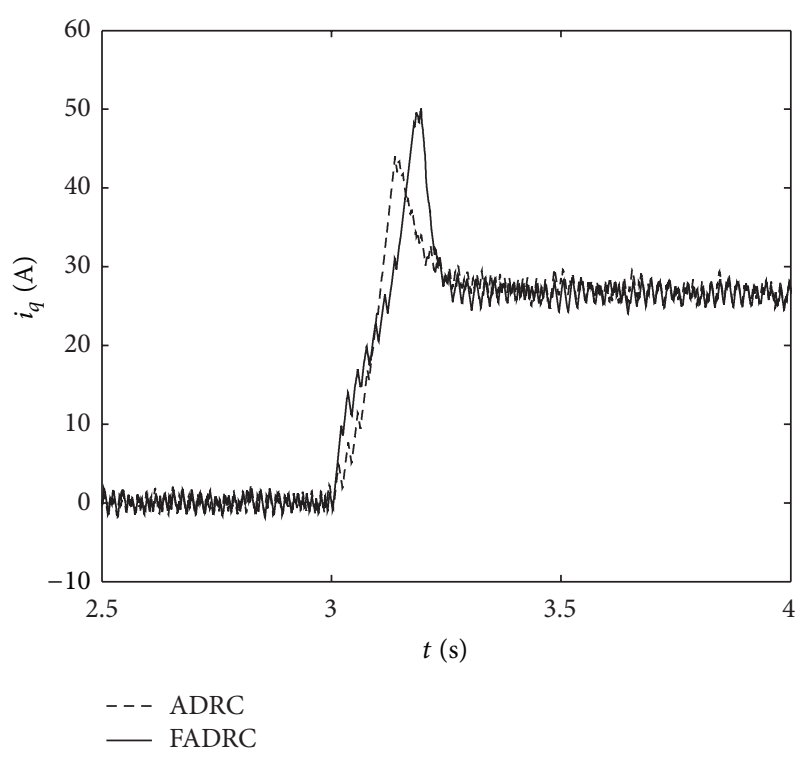

FIgURE 4: $i_{q}$ under the control of ADRC and FADRC.

Figure 3 shows response of the PMSM as the load disturbances vary from $0 \mathrm{~N} \cdot \mathrm{m}$ to $5 \mathrm{~N} \cdot \mathrm{m}$ at $3 \mathrm{sec}$. when it is running at a steady speed of $150 \mathrm{rad} / \mathrm{s}$. solid line represents the speed response of the PMSM under the control of FADRC. Dashed line represents the speed response of the PMSM under the control of ADRC. It can be observed that the PMSM returns to the regulated state very quickly. It indicates that FADRC can give faster compensation when load disturbances occur because fractional order calculus has the nice property of describing the physical object and spreading the stable region of the system parameters as well as the FADRC is simpler to reduce the computing time. The result can be inferred that the speed response of FADRC can still be faster than that of ADRC when load is variable. 


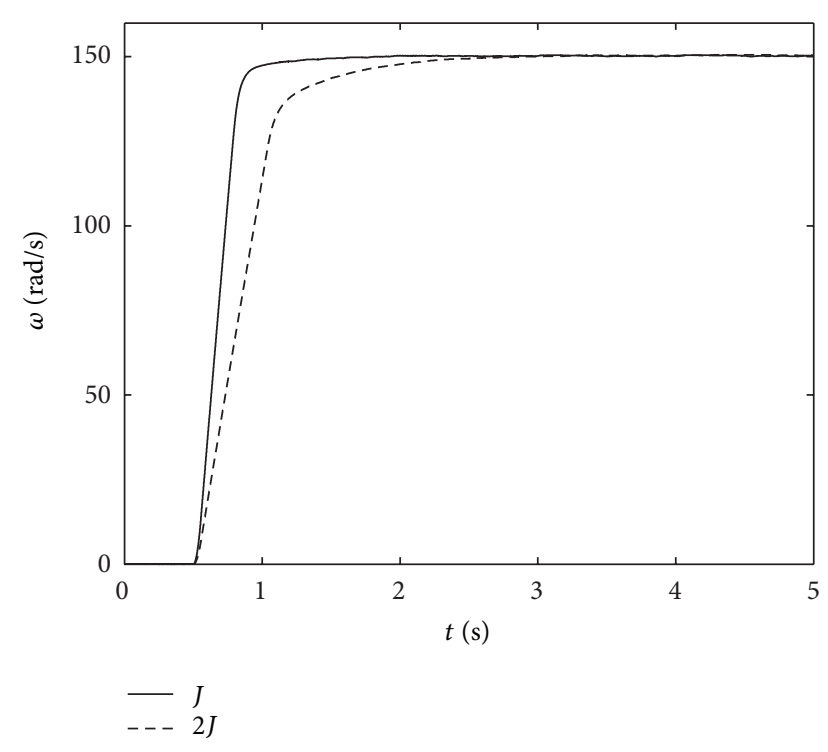

Figure 5: Speed response by different inertia $(J)$ values under the control of ADRC.

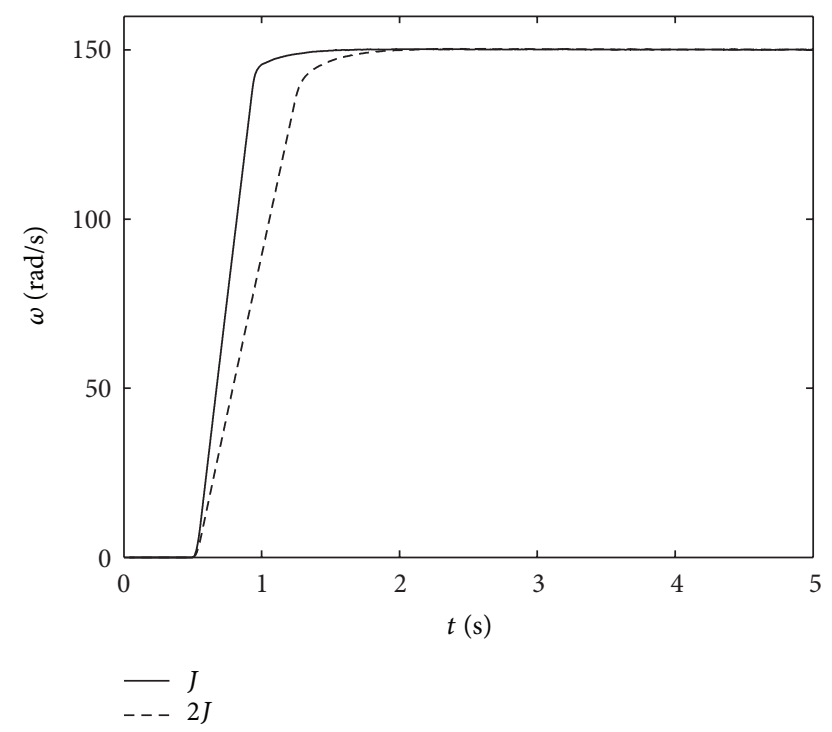

FIGURE 6: Speed response by different inertia $(J)$ values under the control of FADRC.

Quadrature-axis currents of FADRC and ADRC are shown in Figure 4. The quadrature-axis current represents the electromagnetic torque. In Figure 4, the torque of the PMSM under the control of FADRC can be fast response to effectively restrain the load speed ripple caused by disturbances and improve the robustness of system.

Figures 5 and 6 are robustness of the ADRC and FADRC about PMSM inertia parameter varying twice. The results indicate that the regulation time of speed response of FADRC is shorter than that of ADRC. The proposed controller has better robustness.

\section{Conclusions}

A nonlinear feedback active rejection disturbance controlled permanent magnet synchronous motor drive is proposed. In this system fractional order integral is introduced to active rejection disturbance control to replace the nonlinear function in NLSEF, which can efficiently combine the high performance of active rejection disturbance technique observing disturbances with the characteristics of fractional calculus more really describing the physical object and spreading the stable region of the system parameters. It is applied to the permanent magnet synchronous drive. Simulation results show the feasibility and effectiveness of the proposed controller.

\section{References}

[1] Y. S. Kung and M. H. Tsai, "FPGA-based speed control IC for PMSM drive with adaptive fuzzy control," IEEE Transactions on Power Electronics, vol. 22, no. 6, pp. 2476-2486, 2007.

[2] A. Piippo, M. Hinkkanen, and J. Luomi, "Adaptation of motor parameters in sensorless PMSM drives," IEEE Transactions on Industry Applications, vol. 45, no. 1, pp. 203-212, 2009.

[3] R. M. Jan, C. S. Tseng, and R. J. Liu, "Robust PID control design for permanent magnet synchronous motor: a genetic approach," Electric Power Systems Research, vol. 78, no. 7, pp. 1161-1168, 2008.

[4] K. J. Åström and T. Hägglund, “The future of PID control," Control Engineering Practice, vol. 9, no. 11, pp. 1163-1175, 2001.

[5] P. Stewart and V. Kadirkamanathan, "Dynamic model reference PI control of permanent magnet AC motor drives," Control Engineering Practice, vol. 9, no. 11, pp. 1255-1263, 2001.

[6] H. C. Cho, K. S. Lee, and M. S. Fadali, "Adaptive control of pmsm systems with chaotic nature using lyapunov stability based feedback linearization," International Journal of Innovative Computing, Information and Control, vol. 5, no. 2, pp. 479488, 2009.

[7] S. Li and Z. Liu, "Adaptive speed control for permanent-magnet synchronous motor system with variations of load inertia," IEEE Transactions on Industrial Electronics, vol. 56, no. 8, pp. 30503059, 2009.

[8] C. K. Lai and K. K. Shyu, "A novel motor drive design for incremental motion system via sliding-mode control method," IEEE Transactions on Industrial Electronics, vol. 52, no. 2, pp. 499-507, 2005.

[9] F. J. Lin, D. H. Wang, and P. K. Huang, "FPGA-based fuzzy sliding-mode control for a linear induction motor drive," IEE Proceedings Electric Power Applications, vol. 152, no. 5, pp. 11371148, 2005.

[10] T. L. Hsien, Y. Y. Sun, and M. C. Tsai, " $H_{\infty}$ control for a sensorless permanent-magnet synchronous drive," IEE Proceedings Electric Power Applications, vol. 144, no. 333, pp. 173-181, 1997.

[11] S. Cheng, Y.-Y. Huang, H.-H. Chou, C.-M. Ting, C.-M. Chang, and Y.-M. Chen, "PDFF and $H_{\infty}$ controller design for PMSM drive," in Novel Algorithms and Techniques in Telecommunications, Automation and Industrial Electronics, pp. 237-241, Springer, New York, NY, USA, 2008.

[12] A. Caponio, G. L. Cascella, F. Neri, N. Salvatore, and M. Sumner, "A fast adaptive memetic algorithm for online and offline control design of PMSM drives," IEEE Transactions on 
Systems, Man, and Cybernetics, Part B, vol. 37, no. 1, pp. 28-41, 2007.

[13] A. V. Topalov, G. L. Cascella, V. Giordano, F. Cupertino, and O. Kaynak, "Sliding mode neuro-adaptive control of electric drives," IEEE Transactions on Industrial Electronics, vol. 54, no. 1, pp. 671-679, 2007.

[14] K. Y. Cheng and Y. Y. Tzou, "Fuzzy optimization techniques applied to the design of a digital PMSM servo drive," IEEE Transactions on Power Electronics, vol. 19, no. 4, pp. 1085-1099, 2004.

[15] F. J. Lin and C. H. Lin, "A permanent-magnet synchronous motor servo drive using self-constructing fuzzy neural network controller," IEEE Transactions on Energy Conversion, vol. 19, no. 1, pp. 66-72, 2004.

[16] Z. G. Liu and S. H. Li, "Active disturbance rejection controller based on permanent magnetic synchronous motor model identification and compensation," Proceedings of the Chinese Society of Electrical Engineering, vol. 28, no. 24, pp. 118-123, 2008.

[17] Y. X. Su, C. H. Zheng, and B. Y. Duan, "Automatic disturbances rejection controller for precise motion control of permanentmagnet synchronous motors," IEEE Transactions on Industrial Electronics, vol. 52, no. 3, pp. 814-823, 2005.

[18] K. Sun, Z. L. Xu, K. Gai, J. Y. Zou, and R. Z. Dou, "Novel position controller of PMSM servo system based on activedisturbance rejection controller," Proceedings of the Chinese Society of Electrical Engineering, vol. 27, no. 15, pp. 43-46, 2007.

[19] C. M. Qin, N. M. Qi, R. Lü, and K. Zhu, "ADRC fractional order PID controller design of hypersonic flight vehicle," Transactions of Nanjing University of Aeronautics and Astronautics, vol. 28, no. 3, pp. 240-245, 2011.

[20] J. Q. Han, "Auto disturbances rejection control technique," Frintier Science, vol. 1, pp. 24-31, 2007.

[21] M. Kleinz and T. J. Osler, "A child's garden of fractional derivatives," The College Mathematics Journal, vol. 31, no. 2, pp. 82-88, 2000. 


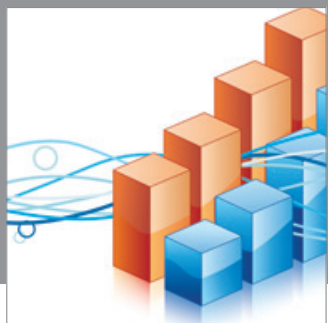

Advances in

Operations Research

mansans

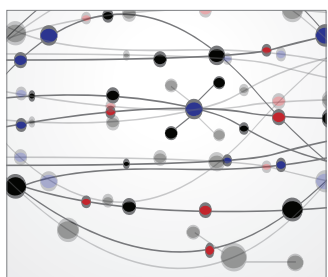

The Scientific World Journal
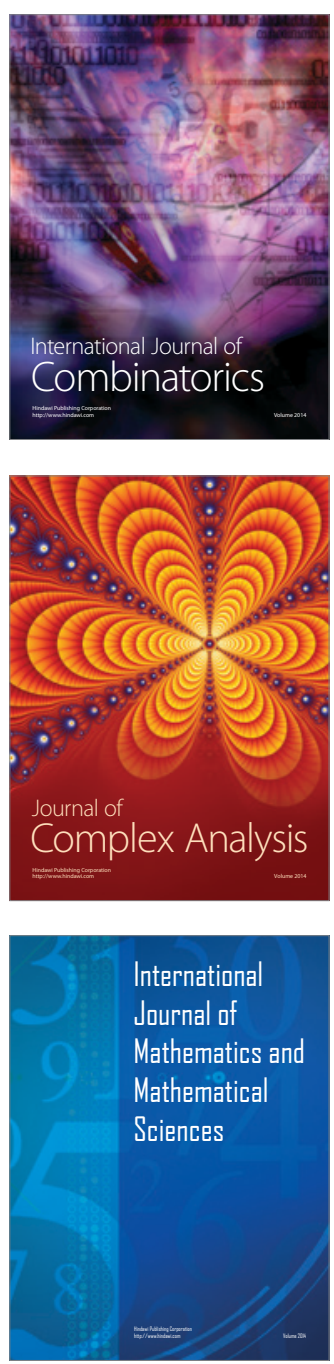
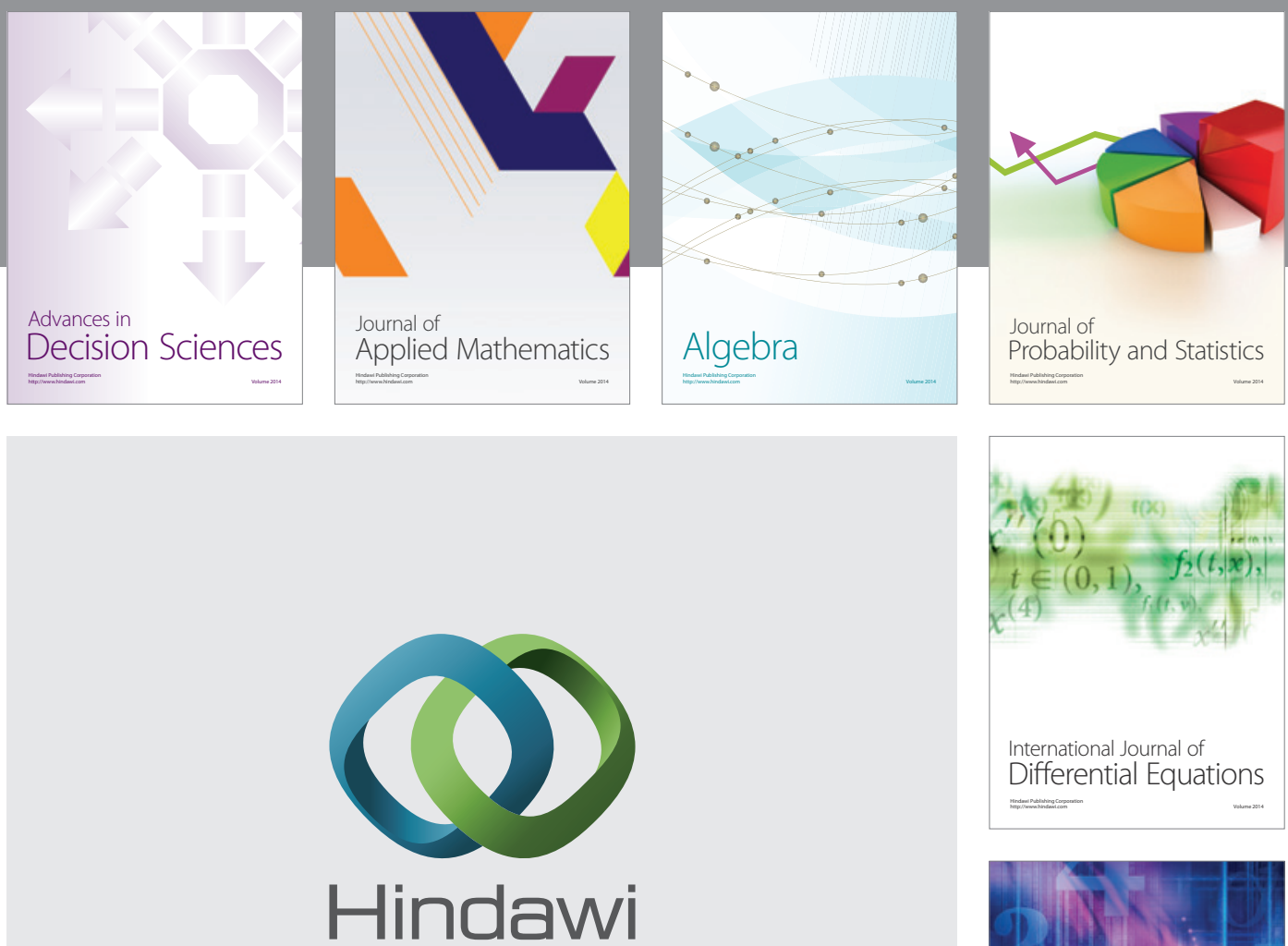

Submit your manuscripts at http://www.hindawi.com
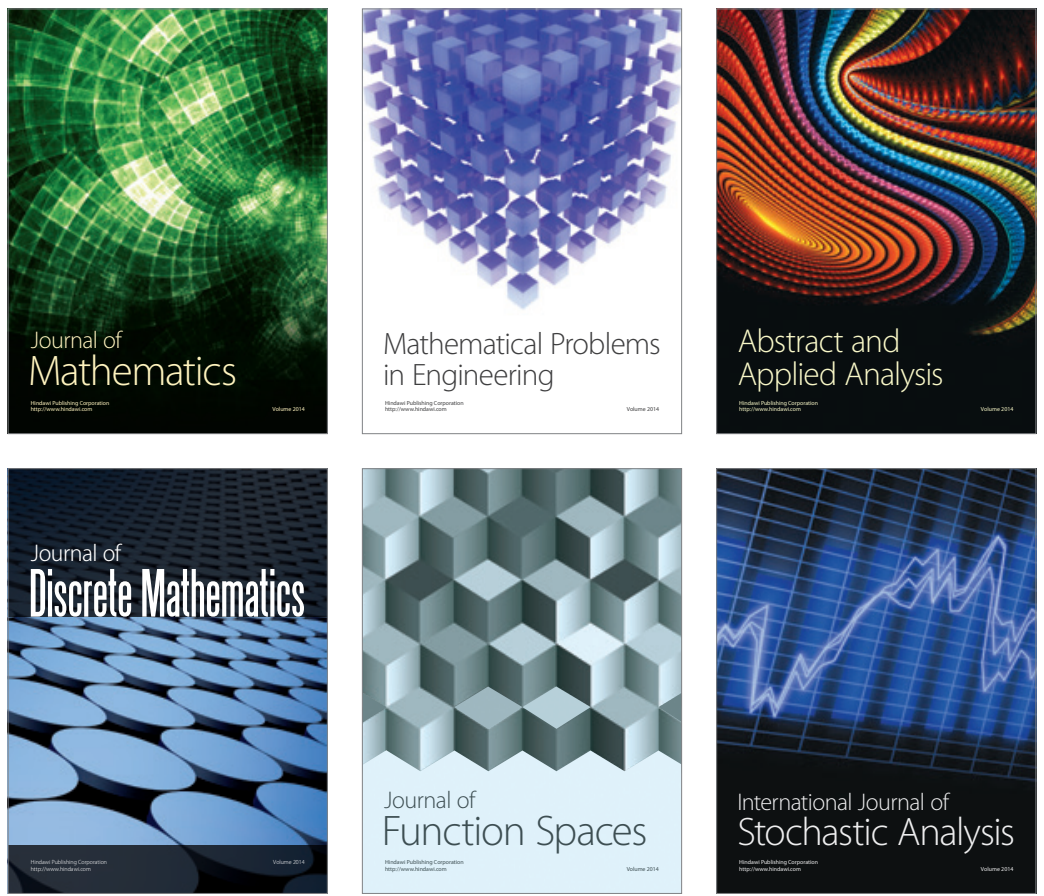

Journal of

Function Spaces

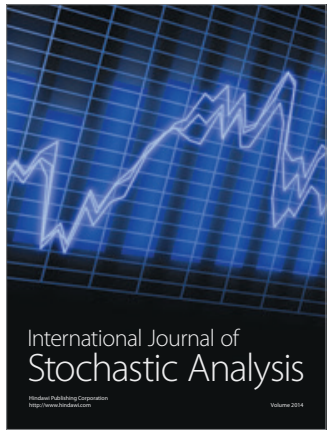

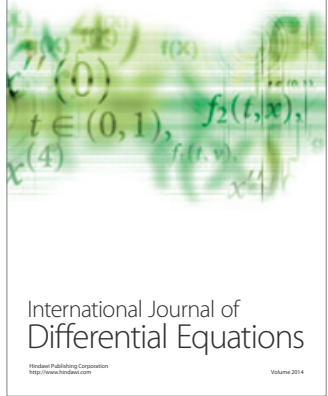
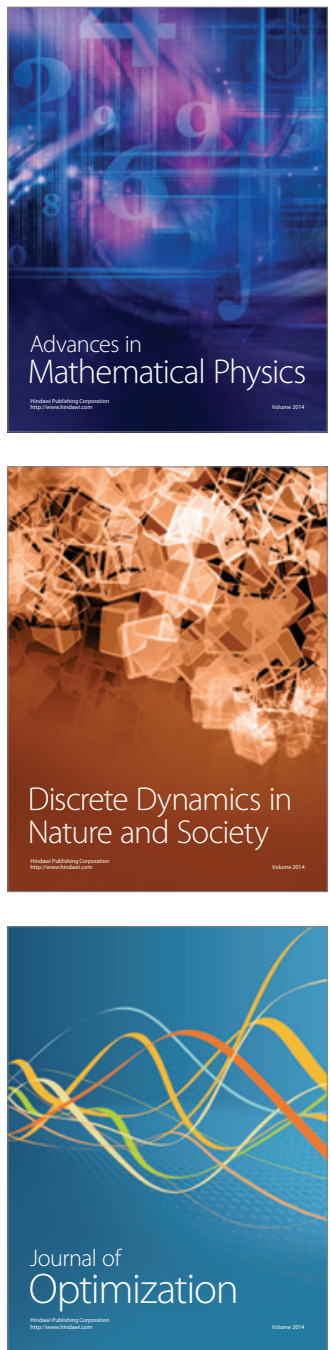